\title{
Development of a biometrically- controlled door system (using iris), with power backup
}

\author{
Engr. Falohun A. S (B.Tech, M.Tech, MCPN, COREN) \\ Engr. Dr. Omidiora E.O. (B.Sc, M.Sc, Ph.D, MCPN, IEEE, COREN, Assoc. Prof.) \\ Engr. Dr. Fakolujo O.A. (B.Sc, M.Sc, Ph.D, MCPN, IEEE, COREN, Assoc. Prof.) \\ Afolabi O..A (B.Tech, M.Tech, Ph.D., MCPN). \\ Oke A.O. (B.Tech, M.Tech, Ph.D., MCPN). \\ Dr. Ajala F.A,
}

\author{
Corresponding author: Engr. Falohun A.S. E-mail:leye_falohun@yahoo.com \\ phone:+234-0803-563-4931
}

\begin{abstract}
This paper presents a design and implementation of a biometrically-controlled door system using iris recognition with power backup(case: Nigeria with epileptic power supply) where user's life property will serve as the key to granting access to a place or resource. Today, door system with handles is sub-standard due to its instability to provide the expected security and is susceptible to breakages and deliberate compromises of human operators(due to corruption). Black iris data sets were used to simulate the iris recognition algorithms employed on the fabricated door prototype. The system was tested with a number of pre-enrolled templates and some fresh, incoming subjects. The door only unlocked for pre-enrolled subjects while for the latter, access denial was the case. The door system developed thus, answered only to iris signature.
\end{abstract}

\section{INTRODUCTION}

The need of security on life and properties in this $21^{\text {st }}$ century cannot be overemphasized, as it is one of the major challenges facing individuals and corporate organizations. From tangible to intangible properties, everyone is becoming more alert to the need for efficient means of security.

Doors are known to provide major functions such as protection, safety to a building or place from any possible invasion. Therefore, the capability of a door system to provide privacy and security when demanded is worthwhile. Automation entails carrying out the jobs that ought to be done by man through the use of machines. Automatic door is a new way of creating doors without the need to manually apply force in the case of doors with handles or keys. Using a computer to control the opening and closing of the door with the use of programming skills makes the door more flexible and adaptable to changes when required. Several security methods in time past have been employed to curb the menace of property theft and absolute destruction but which have all proved insufficient in dealing with this threats on life and properties. From the use of doors with manual lock and key, to the use of doors that use manual combinational lock codes even to mechanical doors, the need for security still abides, with increase in scientific knowledge and technological advancement, a better way of providing security has now been introduced and implemented in developed countries, except in developing nations where it is still unpopular. This technology called biometrics is a process used to identify or authenticate an individual's identity using any of a series of physical or behavioral characteristics instead of what the individual carries like key or knowledge of pass codes. These characteristics include fingerprints, hand or palm geometry, retina and iris scans, facial mapping, signature or writing style, and more recently, DNA maps.(Woodward et.al.,2002), (Wildes, 1997). With biometrically developed security systems, it is not possible to misplace or forget the trait to be measured, which here acts as the key, as it is an inherent feature of the user. Thus, Biometrics provides a safer way to secure both life and properties.

Iris Recognition System: A typical iris recognition system (Du et al., 2005) is shown in Figure 1, which involves four main modules: the image acquisition module, the pre-processing module, the template generation module, and the pattern recognition module: 
$>\quad$ Image acquisition. This module captures one or multiple iris image(s) from the subject using an iris camera.

$>\quad$ Pre-processing. At this step, the image is enhanced first. The enhancement includes contrast adjustment and noise filtering. The next step is to perform edge detection and thresholding. The pupillary boundary (inner boundary of the iris), the limbic boundary (outer boundary of the iris), eyelids, and eyelashes are detected. In this way, the iris patterns can be extracted from the iris image. Usually, normalization between the pupillary boundary and the limbic boundary is performed in this step to reduce the effect of the pupil constrain or dilate.

$>\quad$ Template generation. The extracted iris patterns are not ready for comparison yet. In this step, the template is created from the extracted iris patterns. In the literature, there are various ways to generate the templates, including Gabor wavelet, zero-crossing wavelet, local variance, spatial filters, and 1D local texture pattern approaches.

$>\quad$ Pattern recognition. The newly generated iris template is compared with the iris templates in the database. If a match is found, this iris would be identified. The matching methods include binary code matching method and similarity matching method.

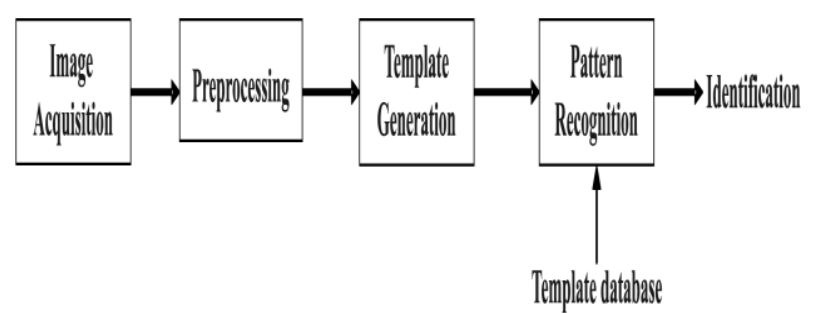

Fig 1. A typical Iris recognition system (source: Du et al., 2005)

Control Engineering: Control Engineering tends to present a system that is an arrangement of one or more physical components connected or related in such a manner as to COMMAND,DIRECT or REGULATES itself or another system.

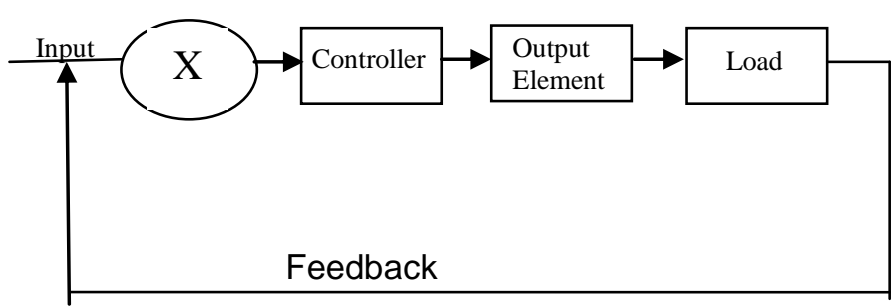

Fig 1: Block Diagram of Closed a Loop Control System

Significance of A Biometrically Controlled Door System With Power Backup: The significance of iris technology among others, for security and access control applications are numerous. In terms of physical security iris technology is already making inroads in the access control market because of its authentication accuracy and its reliability. (Mansfield and Wayman, 2002). This work will overtake situations where access cards are stolen, misplaced or damaged. Apart from this, the security system cannot be easily hacked, unlike other forms of doors, whose padlocks can easily be broken or the key to opening the padlock duplicated, or the access card duplicated or even the combinational code for the door compromised and hacked. Reduction of maintenance cost is another basic relevance of the iris technology access control, due to the centralized control, unnecessary security patrols can be avoided. It is very comfortable to use as it does not involve manual opening and shutting of doors. iris controlled biometric is very stable and reliable compared to other forms of biometric authentication.(Daugman 1993, 2003)

Door System Automation: The extension in the capabilities of machines (door) to perform the job normally is impossible without human interference and this brings about the idea of door automation. Biometrics as a form of software technology is applicable in automation to create security and restrict unrecognized assessment of the machine infrastructure. Door system under this means has easy movement. The automation of the door system with the use of biometrics also needs a source of energy which could either be the use electrical energy or other forms of energy to enhance the opening and closing of the door system.

Proposed Approach: The design of the Iris- based access control door is divided into four major sections/units as shown in the Figure 2 below. These units are combined together to form the working model of the system.

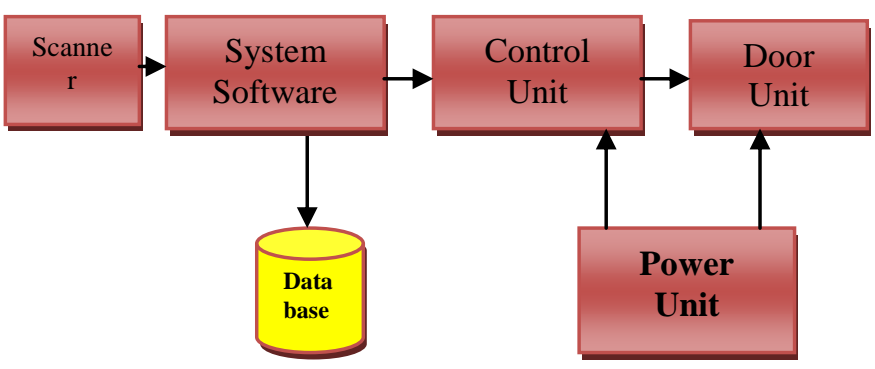

Fig 2. Block diagram of an IRIS Based Access System

Scanner: Iris scanners are hardware that utilizes optical principles to capture the image of human iris. 
Users are expected to stay at a clearly defined distance from the scanner and placement of the eyes is very important as wrongly scanned images will be ignored during extraction by the system software.

System Software: When iris images are captured from the i scanner, the images are loaded into the system software and processed by the software. The software was coded in Matlab.

Control Unit: The control unit consists majorly of a microcomputer Integrated Circuit (PIC16F84A).This microcontroller serves as the intermediary between the software and the door to be controlled. When the Iris is scanned and analyzed, on verification, the authorization is sent to the microcontroller via a serial protocol. The microcontroller will actuate the door unit. The lock will be opened if subject is identified or closed if otherwise. The microcontroller's speed is controlled by the crystal oscillator attached to it. The frequency of the crystal oscillator is divided by four and that gives the speed of the microcontroller.

\section{No of Instructions $/ \mathrm{sec}=\frac{\text { Crystal Oscillator value }}{\text { Dividing factor }}$}

Where the dividing factor for PIC $=4$

No of Instructions $/ \mathrm{sec}=\frac{20000000}{4}=5000000 \mathrm{M} \mathrm{Hz}$

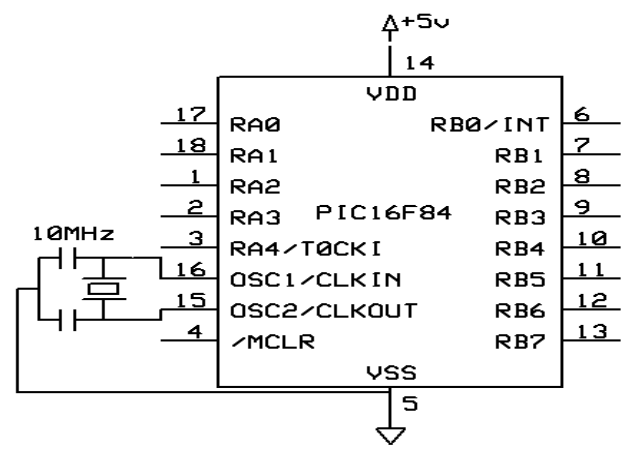

Fig 3 Control Unit

Power Supply: The power supply unit comprises of the transformer T1, Full-wave bridge rectifier DR1, a filter capacitor $\mathrm{C} 1$, and a Regulator $\mathrm{U} 1$ and $\mathrm{a}$ smoothing capacitor C2.

The transformer is a $500 \mathrm{~mA} / 12 \mathrm{~V}$ step down transformer with two anodes; the transformer will step down the 220VAC from the mains to 12VAC that will be needed by the circuit elements. The output of the transformer which is an AC is passed through the rectifier DR1, this will convert the AC supply from the transformer into a DC needed by the components (most electronic components cannot work on AC supply). The output of a rectifier is known to have some ripples which still make the output voltage to behave as a clipped AC source, hence, a filter capacitor $\mathrm{C} 1$ is employed to filter off the $\mathrm{AC}$ ripples so as to give an approximate DC supply (A perfect DC may not be achieved). The easiest way to provide a constant voltage to power circuitry (CPU, op-amps, etc.) is to use a 3 terminal voltage regulator. This is a device which will take a variable input voltage (usually up to 20-30 Volts) and drop it down to a fixed output voltage $(5,12,15$ etc.). It simply dissipates the extra energy, since it draws the same amount of current as it supplies to the load (plus a tiny bit extra to operate itself $\sim$ a few milliamps).

Common Regulators - For currents up to $1 \mathrm{~A}$, the $78 \mathrm{xx}$ and 79xx families of regulators are cheap and easy solutions. The 78xx family is for positive voltages while the 79xx family produces negative voltages (ie: 7805 is a $+5 \mathrm{~V}$ regulator). One characteristic of these regulators is that they require an input voltage of approximately 2 volts more than what you expect to get out of them. This means you'd need $7+V$ to create a steady $5 \mathrm{~V}$ supply. If you expect to actually draw 1A, you will also need to heat sink the chips. They typically come in TO220 packages which can dissipate about $1 \mathrm{~W}$ alone. Suppose you supply a $7805 \mathrm{w} / 8 \mathrm{~V}$ and draw one amp - it will drop the voltage $3 \mathrm{~V}$ and consequently dissipate $3 \mathrm{~W}$ (or overheat and turn off if you don't heat sink it so that it actually can dissipate $3 \mathrm{~W}$ ). The DC output from the rectifier is connected to the input pin of the regulator IC U1 which will regulate the voltage the required $5 \mathrm{~V}$ needed by the TTL PIC, the output of the regulator is connected to a smoothing capacitor $\mathrm{C} 2$ to prevent the effect of voltage spike from having effect on the functionality of the circuit.

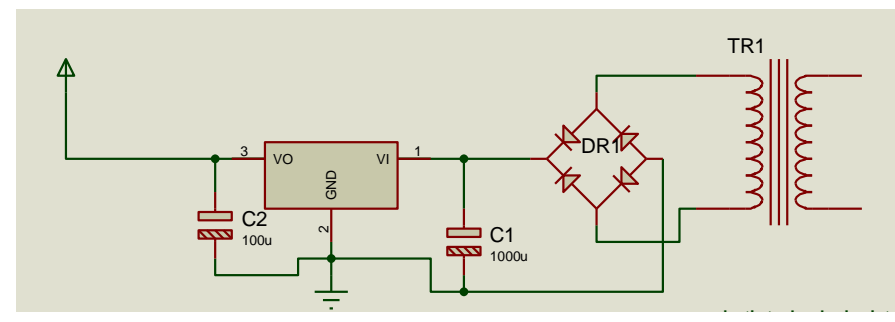

Fig 4 Power supply

For effectiveness of this system, a back-up power unit will be provided, the power unit will be a DC battery which will switch on whenever the power supply goes off. The battery will be in charging mode when the system power supply is still active. The switching speed of the power supply between the mains and the 
back-up battery will be fast such that the functionality of the system will be uninterrupted.

Door Unit: The door unit is made up of an electromagnetic door lock which utilizes little electric signal to switch over from open to close and vice versa. When authentication is sent from the system software to the control unit, the control unit will energize the actuator which unlocks the door lock.

Door Model: Since the design is an access - based system, construction of a modeled door prototype was done using aluminum and transparent glass. To the door was attached the status light indicator that indicates if the door is locked or unlocked. The side of the model was drilled and a hole was made where the power cord and the USB cord was attached. The figure 5 below shows the picture of the model with the hardware circuitry.

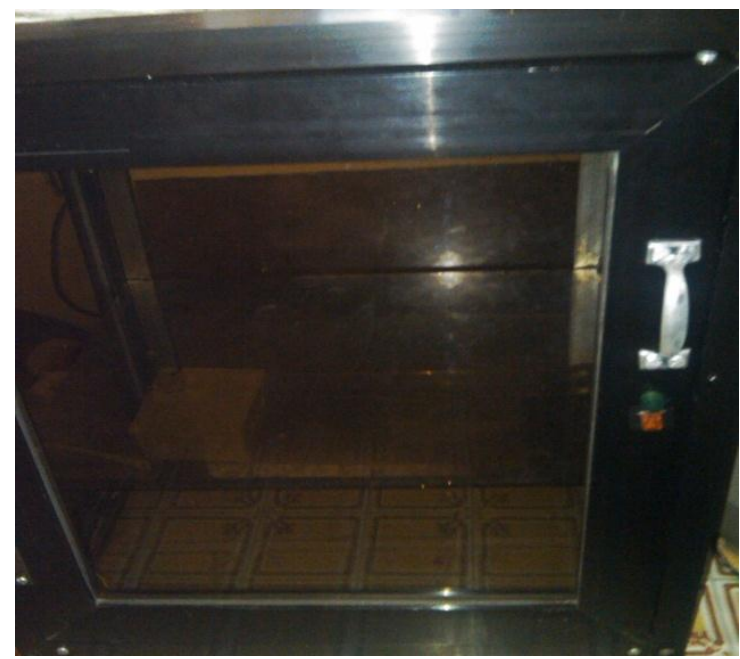

Fig 5 Door prototype model.

Software Design Issue: The following software was used in the design of the interface:

- Matlab 7.9.0 (R2009b).

- Serial - to - USB Driver (DKU software Driver)

The program was written using the Matlab IDE (Integrated Development Environment). The Software was designed to be able to enroll iris templates that has been trained with the software and identied to give authorization to open the door. Figure 6 shows the software interface for the system.

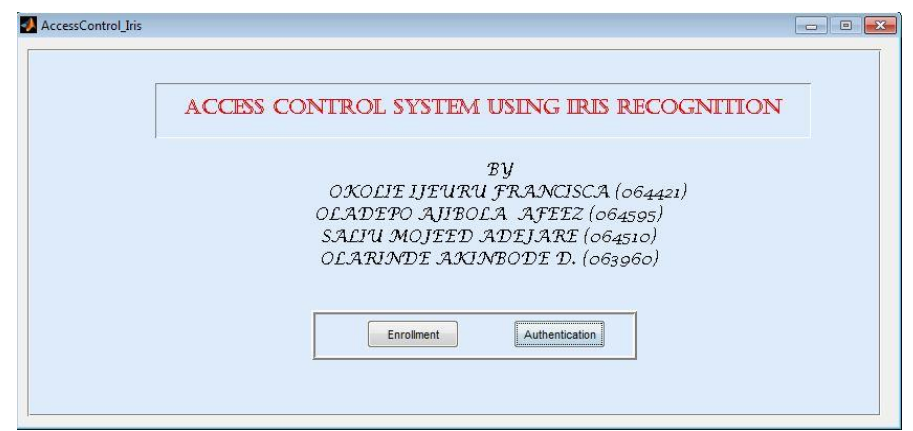

\section{Fig 6 Software Interface}

\section{RESULTS AND DISCUSSION}

The proposed system has been tested with a number of iris templates, and is found to work accurately i.e restricting access request to impostors while granting access to the legitimates. Figures $7 \& 8$ shows the working interface of the system.

Registration Interface: This interface presents the registration platform for the iris template where the iris template is loaded and registered with a unique user name. The registered iris template is processed and saved in the database (Figure 8).

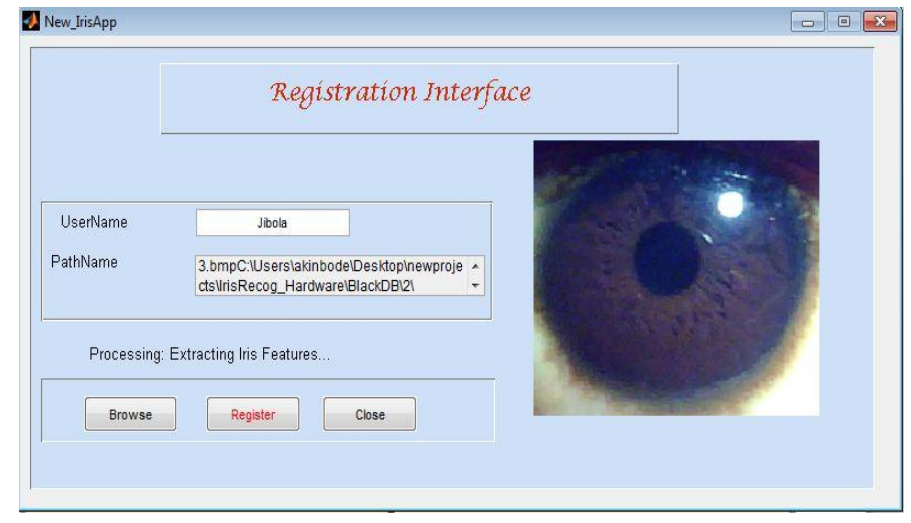

Fig 7 Registration Interface

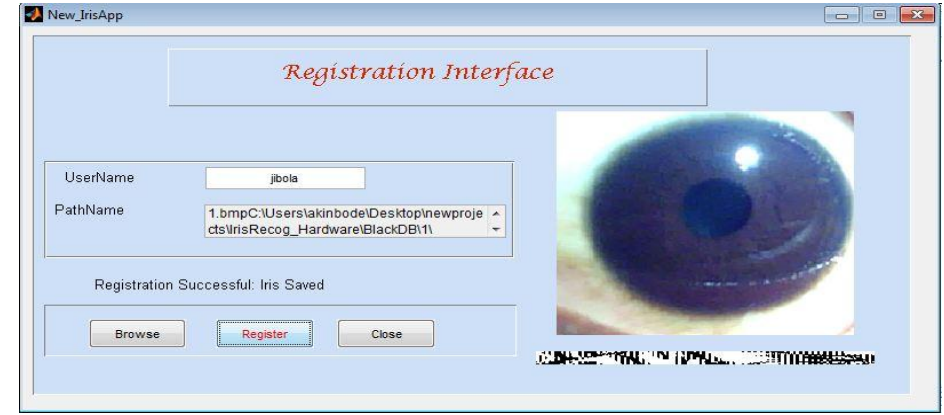

Fig 8 Extracted Iris 
Authentication Interface: This interface compares the already registered iris template with the captured template. Figure 9 shows a matched template which prompted a green light indicator on the door to facilitate an opening and thus, granting access. But in a situation of 'non-match', an error message "iris not recognized: access denied" is flagged (figure 10) and the door remains locked with a RED light indication on the door model.

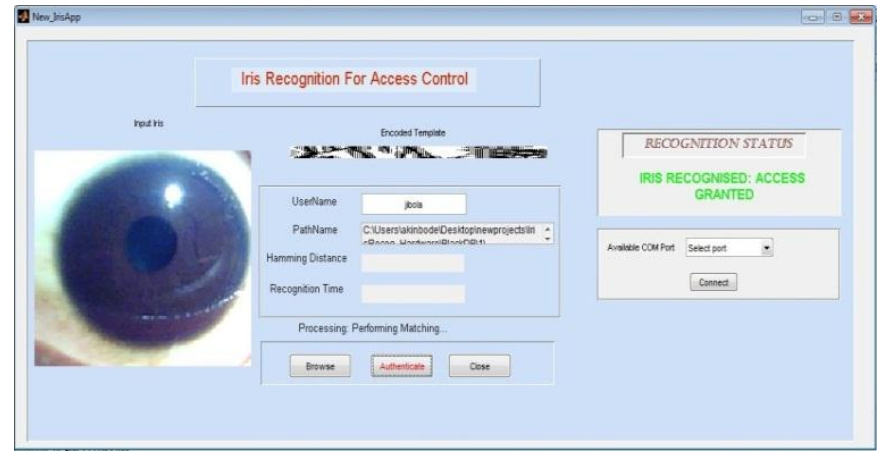

Fig 9 Authentication interface showing access granted

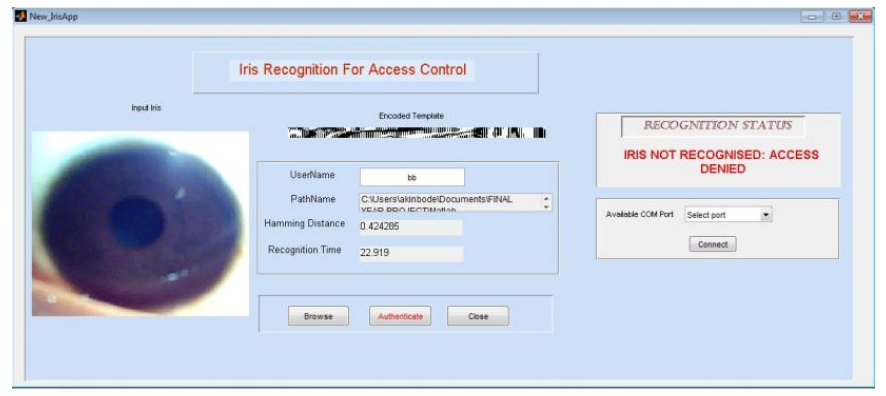

Fig 10 Authentication interface showing access denied

\section{CONCLUSION}

A biometrically - controlled door system using iris template with a power backup has been successfully designed and constructed. The hardware was successfully designed and constructed and a computer program that enables the door to be operated by an electric circuit was also developed. Observation has shown that the application of automated door reduces reliance on human beings; little or no man is needed for the opening and closing of the door and therefore a greater level of security and efficiency is ensured. The prototype can be implemented in real life to prevent theft and increased security.

\section{ACKNOWLEDGEMENT}

Many thanks we give to the director, Biometric Research Centre (a World Bank assisted Biometric Centre in Nigeria), Professor T.S Ibiyemi of the department of Electrical Engineering, University of llorin, ilorin, Nigeria for providing us all the iris capturing equipments used in this work. The Centre's contributions really helped in our image acquisition and pre-processing activities.

\section{REFERENCES}

1. Daugman J., (1993) "High Confidence Visual Recognition of persons by a test of Statistical Independence". IEEE Transactions on Pattern Analysis and Machine Intelligence, 1148 - 1161 .

2.Daugman, J., (2003), "The importance of being random: statistical principles of iris recognition", Pattern Recognition: 36(2): 279-291.

3. Daugman, J.(2004), "How iris recognition works. IEEE Transactions on Circuits and Systems. For Video Technology 14: 1: pp 21-30.

4. Yingzi, Du., Bonney, B., Ives , R., Etter, D., Schultz, R.,( 2005), IEEE International Conference on signal processing.

5. Mansfield,T and Wayman, J.L (2002) "Best practices in testing and reporting performance of biometric devices." on the web at www.cesg.gov.uk/biometrics.

6. Nagrath I.J.( ) , Control Systems Engineering, Fourth ed. Wiley Eastern Limited, New Delhi, india. pg 134

7. Wildes $\mathrm{R}(1997)$, "Automated iris recognition: An emerging Biometric technology," Proceeding of the IEEE 85 pp 1348-1363.

8. Woodward, Orlans, and Higgins.( 2003), "Biometrics /Authentication Technology " on the web at biometrics.pbworks.com/w/page/14811351/Authenticati on technologies. 